\title{
Área de Proteção Ambiental do Maracanã em São Luís (Maranhão, Brasil): aspectos socioambientais e o desenvolvimento local na atividade turística
}

\section{Maracanã Environmental Protection Area in São Luís (Maranhão, Brazil): social and environmental issues and local development in tourist activity}

\author{
Saulo Ribeiro dos Santos (SANTOS, S. R. dos) ${ }^{*}$ e \\ Protásio Cezar dos Santos (SANTOS, P. C. dos) ${ }^{* *}$
}

\begin{abstract}
RESUMO - Objetiva-se neste artigo identificar como o fenômeno turístico contribuiu responsavelmente para a eqüidade do desenvolvimento local da comunidade do Bairro do Maracanã, no município de São Luís (Maranhão, Brasil). A partir de uma revisão teórica do tema, e da pesquisa realizada com os autóctones, obteve-se a possibilidade de entender a real importância do turismo para o desenvolvimento social e local no bairro do Maracanã. Os resultados apontam que o turismo desenvolvido no Maracanã é um aporte para o alcance de uma qualidade de vida para os moradores do bairro e que os projetos turísticos quando bem direcionados, criam uma massa crítica sobre o conceito de preservação do meio ambiente. Conclui-se que, a maneira como o turismo vem sendo desenvolvido no Maracanã está trazendo efeitos benéficos a todos, fazendo com que a comunidade envolva-se com a atividade turística, recebendo os aportes positivos que o turismo proporciona.
\end{abstract}

Palavras-chave: Responsabilidade Social; Turismo; Maracanã; Desenvolvimento Local.

ABSTRACT - The objective of this paper is to identify how the tourist phenomenon contributed responsibly to the equity of the local development of 'Bairro Maracanã' community, in São Luís (Maranhão, Brazil). From a theoretical review of the issue and of a field research accomplished with the locals, it was obtained the possibility of understanding the tourism real importance for the social and local development of the Maracanã neighborhood. The results show that the tourism developed in Maracanã is a contribution to the achievement of a quality of life for the residents of that area and the tourism projects when well directed, create a critical mass about the concept of environmental preservation. It is concluded that the way how tourism is being developed at 'Bairro Maracanã' is bringing benefits to all people involved, making the community get involved with tourism and receiving the positive contributions that this activity provides.

Key words: Social Responsibility; Tourism; Maracanã; Local Development.

\footnotetext{
* Graduação em Turismo pela Faculdade Atenas Maranhense. Especialização em Turismo: planejamento, gestão e marketing pela Universidade Católica de Brasília. Mestrado em Administração e Desenvolvimento Empresarial pela Universidade Estácio de Sá. Professor do Departamento de Turismo e Hotelaria e do Curso de Administração (Virtual) da UFMA. Endereço: Rua Minerva, 9, Qd. 27, Ap. 501, Renascença 2. CEP: 65075-035 - São Luís - Maranhão (Brasil). Telefax: (98) 8181-0228. E-mail: saulosantosma@uol.com.br

** Graduação em Relações Públicas (UFMA). Mestrado em Comunicação pela Universidade Federal do Rio de Janeiro. Doutorado em Desenvolvimento Sustentável do Trópico Úmido, com área de concentração em Ciências Ambientais (UFPA). Professor no Curso de Comunicação Social (UFMA). Professor na Universidade Estadual do Maranhão no Departamento de Ciências Sociais e no Mestrado em Desenvolvimento Socioespacial e Regional. Endereço: Rua Minerva, 9, Qd. 27, Ap. 501, Renascença 2. CEP: 65075-035 - São Luís - Maranhão (Brasil). Telefax: (98) 8114-6015. E-mail: labcom17@bol.com.br
} 


\section{INTRODUÇÃO}

O mundo passa por diversas transformações nos âmbitos ambientais, culturais e principalmente socioeconômicos com relação à busca por novas fontes de riquezas e desenvolvimento. Desta forma, nota-se um crescente surgimento do turismo como opção de integração sistêmica dos aspectos citados, pois o turismo alinha-se ao conceito de desenvolvimento, no que tange às contribuições econômicas e sociais, a partir de políticas públicas direcionadas e planejamento ordenado. Corroborando, enfatiza-se que benefícios como infra-estrutura básica, saneamento, inclusão social, preservação ambiental e outros venham somar para a melhoria na qualidade de vida, é importante destacar que o planejamento turístico auxilia na construção de uma atividade limpa e responsável, a partir de sua execução e continuidade.

Nesta esteira social, este estudo identifica que o turismo desenvolvido no bairro do Maracanã, na cidade de São Luís, no estado do Maranhão (Brasil), está voltado para a questão ecológica, com caráter sustentável, mas que também conta com princípios da responsabilidade social, envolvendo a comunidade nas atividades, principalmente nas trilhas ecológicas da Área de Proteção Ambiental do Maracanã (o bairro faz parte da APA do Maracanã), ampliando as opções de lazer e promovendo a geração de renda, trabalho e consequentemente a qualidade de vida dos autóctones da região.

Portanto, o objetivo desta pesquisa foi o de identificar como a atividade turística contribuiu responsavelmente para a eqüidade do desenvolvimento local da comunidade do Bairro do Maracanã.

Para dar suporte ao estudo, utilizou-se de pesquisa bibliográfica e documental, pois são tratados conceitos sobre planejamento, responsabilidade social, desenvolvimento local e atividade turística e seus impactos. Além de pesquisa de campo com moradores do bairro do Maracanã. A pesquisa é de caráter descritivo, na medida em que busca expor as contribuições do turismo no bairro do Maracanã, juntamente à comunidade, diante de atividades de valorização do turismo.

Almeja-se com este estudo, demonstrar a real importância de se desenvolver ações sociais em algumas comunidades, em especial com auxílio da atividade turística, contribuindo assim, para o desenvolvimento mútuo do turismo nestas localidades. 
Para melhor elucidar o artigo, têm-se como tópicos definições acerca de planejamento turístico, políticas de turismo, desenvolvimento local, gestão social do turismo e os resultados ${ }^{1}$.

\title{
2 DESCOBRINDO O TURISMO E O PLANEJAMENTO TURÍSTICO
}

As atividades vinculadas ao turismo não estão relacionadas apenas ao deslocamento de pessoas, mas também estão direcionadas com lazer, saúde, negócios, conhecimentos socioeconômicos e culturais, dentre outros. É também uma forte influência sobre a economia mundial e, conseqüentemente, no estilo de vida das sociedades no decorrer do tempo, pois é encarado como uma das principais fontes de geração de divisas, ocorrendo em alguns casos de lugares dependerem quase que exclusivamente desta atividade. Silveira (2002, p. 87) acrescenta que o turismo é "classificado como a principal atividade econômica do mundo, superando até mesmo o petróleo em geração de divisas internacionais, o turismo tornou-se 'objeto de desejo' para muitas regiões".

Mas, para que o turismo contribua para com a economia local, é necessário um planejamento que ordene as ações em prol do desenvolvimento qualitativo. Então, afirma-se que o planejamento turístico é o ato de traçar, projetar um plano para a atividade turística, objetivando o correto funcionamento desta. Já para Estol e Albuquerque (s. d, p. 8 apud RUSCHMANN, 1997, p. 84)² é:

\begin{abstract}
Um processo que consiste em determinar os objetivos de trabalho, ordenar os recursos materiais e humanos disponíveis, determinar os métodos e as técnicas aplicáveis, estabelecer as formas de organização e expor com precisão todas as especificações necessárias para que a conduta da pessoa ou do grupo de pessoas que atuarão na execução dos trabalhos seja racionalmente direcionada para alcançar os resultados pretendidos.
\end{abstract}

Nota-se não só a importância, mas a necessidade do planejamento, pois os lugares turísticos esperam com a atividade, tanto desenvolvimento econômico quanto equidade social. Entretanto, nesta busca imediatista pelo desenvolvimento, ocorre de

\footnotetext{
${ }^{1}$ A versão preliminar deste trabalho foi apresentada no VII Encontro da Sociedade Brasileira de Economia Ecológica em 2009.

${ }^{2}$ ESTOL, E.; ALBUQUERQUE, S. Planeamiento turístico. Buenos Aires, Ciet, s. d.
} 
muitos passarem "por cima" do planejamento turístico, cometendo atos e instituindo ações onde muitas vezes criam quadros problemáticos ou até mesmo irreversíveis da falta de visão dos efeitos do turismo.

\subsection{POLÍTICAS DE TURISMO: AÇÕES PARA O DESENVOLVIMENTO DA ATIVIDADE}

Viver em sociedade é um processo complexo, devido ao convívio constante entre pessoas, com seus hábitos, costumes e modos de vida. Por outro lado, o mundo seria bem mais conturbado sem sua existência, pois a sociedade é plurarista com diversas crenças, etnias, opiniões e projetos. Desta forma, se faz necessário existir governantes atuando na vida pública e com poderes para destinar determinado rumo à sociedade, em busca de um interesse comum.

A complexidade continua, principalmente pelo fato da atividade turística promover a ligação direta do homem com novas culturas distintas, ou seja, visitantes e comunidades receptoras, onde deve existir o respeito mútuo. E para minimizar esta complexidade, autores como Goeldner, Ritchie e Mcintosh (2002, p. 294 apud SOLHA, 2006, p. 91) ${ }^{3}$ esclarecem que política de turismo é:

Um conjunto de regulamentação, regras, diretrizes, diretivas e estratégias de desenvolvimento e promoção que fornece uma estrutura na qual são tomadas as decisões coletivas e individuais que afetam diretamente o desenvolvimento turístico e as atividades diárias dentro de uma destinação.

Portanto, se tem a política de turismo como fator predominante para $\mathrm{o}$ desenvolvimento, por orientar para um plano e com as iniciativas voltadas para investimentos no setor. Complementando este aspecto, na visão de Solha (2006, p. 89) a política do turismo funciona como moderadora da atividade, através de decisões e práticas estratégicas de longo prazo, ou seja, "a política pode e deve ser flexível, dinâmica e estar [...] adequada aos interesses e características de cada povo, época e do âmbito geográfico em que será aplicada".

O governo como elaborador de políticas, deve estar atento não só no alcance de

\footnotetext{
${ }^{3}$ GOELDNER, C. R.; RITCHIE, J. B.; MCINTOSH, R. W. Turismo: princípios, práticas e filosofias. Porto Alegre, Bookman, 2002.
} 
resultados financeiros, mas também desencadear uma evolução igualitária que traga benefícios a toda comunidade.

Em outras palavras, o processo de formulação de uma política do turismo tem que levar em consideração a ampla segmentação da atividade, para não existir favorecimento de uma em detrimento de outra, ocasionando discórdia entre o próprio trade e também a comunidade receptora. Tais cuidados devem ser priorizados ao passo que "segmentos da população podem discordar sobre os impactos percebidos do turismo e empresas podem competir para direcionar o desenvolvimento de forma que as favoreça" (OMT, 2003, p. 193).

O trade e a comunidade devem estar inclusos neste processo, sendo pontos de apoio e feedback contínuo, para o desenvolvimento ético das políticas e com papéis fundamentais nas relações humanas do turismo, atingindo-se um nível satisfatório para todos os envolvidos.

Certamente, pode-se usufruir das experiências de outras localidades, para não se cometer os mesmos erros, enxergando nestas um ponto de auxílio no desenvolver das próprias diretrizes, pois cada local reflete suas peculiaridades e reage das mais diversas formas às mudanças.

\subsection{TURISMO E DESENVOLVIMENTO LOCAL: UMA PARCERIA DE SUCESSO}

A partir da década de 80, as nações passam a questionar e buscar meios para resolver as suas problemáticas internas, e certamente depararam com sérios problemas, que podem ser resolvidos, através da articulação local, em prol do desenvolvimento. Trazendo para a questão do local, este ganha crescente enfoque, pois "o local (re) surge impulsionado pela globalização, que se nutre das especificidades locais, a partir de suas potencialidades e identidades" (SOUSA, 2006, p. 12). Do mesmo modo, Zapata (2004, p. 1) afirma que:

O conceito de desenvolvimento local se apóia na idéia de que as localidades e territórios dispõem de recursos econômicos, humanos, institucionais, ambientais e culturais, além de economias de escalas não exploradas, que constituem seu potencial de desenvolvimento. 
Todavia, cabe ressaltar que o desenvolvimento local por valorizar o desenvolvimento humano, é visto como resposta aos efeitos da globalização, de centralização, padronização e busca crescente do fator econômico, pois "o capitalismo globalizado hierarquiza os processos de decisão e informação, através de redes produtivas e financeiras, ao territorializar os centros de decisão e ao separar os espaços de execução das funções de produção" (BOCAYUVA apud CAMPOS, 2003, p. 49) ${ }^{4}$.

Por sua vez, o desenvolvimento local adquire mais força ao difundir as peculiaridades de cada local e por tratar as comunidades como parte integrante e indispensável no processo de tomada de decisões para o desenvolvimento. Complementando, Zapata (2001, p. 116 apud CAMPOS, 2003, p. 52) ${ }^{5}$ entende que no desenvolvimento local:

Finalísticamente, busca-se a melhoria da qualidade de vida da população, maior participação nas estruturas de poder, ação política com autonomia e independência, compreensão do meio ambiente como um ativo de desenvolvimento e construção de novos paradigmas éticos que apontem para modelos de desenvolvimento mais sustentáveis, que contribuam para a felicidade e realização humana.

É importante registrar que a modificação na estrutura das políticas públicas, tem tornado o poder mais descentralizado, diante da tendência da participação local. Neste sentido, é bom lembrar que o pressuposto da peculiaridade de uma região está ligado ao planejamento das políticas em prol do desenvolvimento local, e não apenas ao ponto de vista macro.

Recomenda-se ainda que para o sucesso objetivado pelo desenvolvimento local são necessários cinco aspectos básicos, sendo estes: geração de oportunidades de capitalização; geração de benefícios sociais; equidade na distribuição dos benefícios gerados; eliminação da discriminação e a elaboração de mecanismos efetivos de participação da comunidade (RUFINO, 2003 apud PENA JÚNIOR; VÁLERY, 2005) ${ }^{6}$.

\footnotetext{
4 BOCAYUVA, P. C. C. Incubadora Tecnológica de Cooperativas Populares/COPPE/UFRJ. In: CAMAROTTI, I.; SPINK, P. (Orgs.) Redução da Pobreza e Dinâmicas Locais. Rio de Janeiro: FGV, 2001.

${ }^{5}$ ZAPATA, T. et al. Desenvolvimento local: estratégias e fundamentos metodológicos. Rio de Janeiro: Ritz, 2001.

${ }^{6}$ RUFINO, S. Redes de Cooperação Solidária na contribuição do desenvolvimento local. In: ENCONTRO NACIONAL DE ENGENHARIA DE PRODUÇÃO. Anais Eletrônicos. Ouro Preto, ABREPO, 2003.
} 
Então, diante das questões levantadas pela temática do desenvolvimento local juntamente com a integração dos fatores políticos, econômicos e socioculturais, pode-se trazer à tona o setor turístico como uma das atividades mais utilizadas pelos governos nessa concepção de política pública do desenvolvimento.

E a crescente disseminação das ações sustentáveis, principalmente no turismo, tem sido debatida de forma a contribuir na mitigação da degradação ambiental e cultural. Assim, procura-se propor atividades mais brandas diante do grande poder de impacto que possui, pois "sem dúvida, a adoção do conceito do desenvolvimento sustentável aplicado ao turismo representa estratégia válida para se buscar a integração entre uso turístico, preservação do meio ambiente e melhoria das condições de vida nas comunidades locais" (SILVEIRA, 2002, p. 88).

Então, se parafraseando com este autor, percebe-se a integração e contínua complementação entre planejamento, turismo e a sustentabilidade para o advento do desenvolvimento local, em que o autor Barbosa (2005, p. 111) afirma que:

[...] o desenvolvimento do turismo com base local representa uma saída as tendências de produção de uma imagem esteriotipada [...]. Evita que haja devoração da paisagem, degradação do meio ambiente e descaracterização de culturas tradicionais.

Assim, eleva-se o desenvolvimento turístico local ao patamar de um processo planejado visando sustentar características singulares de cada local e que são utilizadas como atrativos turísticos.

\section{GESTÃO SOCIAL E TURISMO: UMA OBRA CONJUNTA}

Trabalhar o turismo como uma empresa no universo da Responsabilidade Social (RS), é buscar identificar quão próximas podem estar estas duas vertentes. Abreu (2006, p. 354) mostra que:

Com esse crescimento do turismo, a sua influência no aspecto econômico de uma determinada localidade tornou-se evidente, desvirtuando e desfocando o aspecto social que o turismo representa, [...], ou seja, esse fenômeno envolve antes de tudo, pessoas. É um ramo das ciências humanas que transcende a esfera econômica. 
Então, diante desse envolvimento do turismo com o âmbito social, este se estende ao mérito da RS, que apesar de ainda não estar conceituada de forma plena, vem obtendo espaço nas discussões sobre a sociedade. Sendo esta utilizada crescentemente no contexto da melhoria da qualidade de vida, principalmente pelo setor privado.

A participação de todos os interessados no desenvolvimento da atividade é visualizada na implementação da RS nas empresas, onde todos os personagens de suas ações são apontados como base para a tomada de decisões, sendo estes chamados de stakeholders ${ }^{7}$.

Por sua vez, a RS cada vez mais enfatiza a participação dos menos favorecidos para que as localidades se desenvolvam, diante de problemas como a concentração de renda, pouca educação, emprego e renda. Complementando, Pinto (2003, p. 15) esclarece que:

É exatamente nesse quadro que a sociedade organizada - pessoas, voluntariado, instituições filantrópicas, instituições beneficentes, organizações não-governamentais, segmento empresarial - vem ressaltando que, para fazer face ao desafio social, tornam-se imprescindíveis, além da conscientização, a expansão de ações complementares - uma mobilização econômico-social que vise a continua melhoria da qualidade de vida e do bem-estar social dos setores carentes e mais fragilizados.

Desta forma, tenciona-se a incluir responsavelmente estes setores mais fragilizados ao usufruto dos benefícios de se viver bem e ser visto realmente como um cidadão participando ativamente da vida social. Somando-se a toda diversificação e características próprias e peculiares da comunidade a que pertencem, e mediante a eqüidade, valorizar seus diferenciais e alavancar a vida social e a implantação e contribuição da atividade turística. A propósito Silva e Boia (2006, p. 13) alegam que:

A inclusão em todos os setores da sociedade significa que essa deve, além de garantir espaços adequados para todos, aceitar e valorizar a diversidade humana. É com este enfoque que saindo do eixo econômico para assumir seu papel na sociedade inclusiva, o turismo é redimensionado, assumindo, nesse contexto histórico específico, um papel de reorientação dos espaços e atitudes sociais.

No momento em que a atividade turística é implantada, visando inserir a sociedade no processo, cabe, portanto, aos gestores, a responsabilidade de gerir

\footnotetext{
${ }^{7}$ Uma pessoa, um grupo ou organização que tenha direta ou indireta participação em uma organização, porque pode afetar ou ser afetados pela organização, ações, objetivos e políticas.
} 
corretamente este fenômeno, para que os impactos positivos sejam maximizados. Por isso, é importante o envolvimento do poder regulador para as ações desenvolvidas. Para facilitar a compreensão deste aspecto, Lage e Milone (2001, p. 211) mencionam que "é importante considerarmos a participação especial de dois agentes econômicos - a organização nacional do turismo, funcionando como uma empresa turística pública e o governo". Portanto, o envolvimento destes agentes é condição sine qua non para o alcance de um turismo socialmente responsável, que respeite os valores e insira a comunidade no contexto.

Mas, apesar dessa atenção que vem sendo destinada para a RS, esta encontra, como qualquer outra vertente que busca sua afirmação, empecilhos para tal, sendo que uma das principais barreiras enfrentadas pela RS é o fato de muitos crerem que esta cabe somente ao governo. Machado Filho (2006, p. 28) confirma essa problemática ao mostrar que na visão destes indivíduos "ao governo caberia a alocação de recursos advindos de impostos e taxas gerados a partir da atividade econômica privada, visando à redistribuição de renda e a alocação mais eficiente dos recursos para aspectos sociais".

Adicionando o pensamento acima, é possível a criação de meios financeiros para contribuir com a equidade social, sendo que o turismo pode ser trabalhado na localidade e com o fluxo de visitantes, promover a criação de acréscimos (taxas) em diárias de hotel, aluguel de carros, entre outros, que podem ser destinados a projetos sociais em comunidades carentes.

Por outro lado, a participação da comunidade de forma ativa no processo de mudanças, é de suma importância para se combater situações de completa pobreza em várias localidades do mundo, sendo importante entender que:

[...] a pobreza gera marginalidade e essa alimenta a pobreza. Na realidade, os pobres não participam da vida econômica, nem da social, nem da política. Estão excluídos do mercado, e sua presença política ou influência social mantêm-se mais no plano formal do que no real. Na realidade ao excluir os pobres da economia e da sociedade, nega-lhes o direito de lutarem para livrarem-se da pobreza (KLISKSBERG, 1997, p. 25 apud FISCHER, 2006, p. 153$)^{8}$.

Por essa exclusão e esta desigualdade social, é que cada vez mais a RS enfatiza a participação dos menos favorecidos ativamente no processo de transformação, visando

\footnotetext{
${ }^{8}$ KLIKSBERG, B. O desafio da exclusão: para uma gestão eficiente. São Paulo: FUNDAP, 1997.
} 
o desenvolvimento social. E, cabe também através do protagonismo comunitário mostrar os indivíduos como cidadãos, pois como caracterizam Aranha e Martins (2005, p. 268):

\begin{abstract}
O cidadão é um sujeito de direitos cívicos e de direitos sociais. Os primeiros consistem, entre outros, na segurança, na igualdade perante a lei e na liberdade de pensamento, expressão, religião, opinião e movimento. Os sociais são os direitos à saúde, à educação, ao trabalho, ao lazer, ao acesso à cultura, bem como à proteção em caso de desemprego e doença etc. Em contrapartida, o cidadão é um sujeito de obrigações, tais como o pagamento de impostos, a responsabilidade coletiva, a solidariedade e a participação efetiva, o que significa desempenhar uma cidadania ativa, que vai muito além do ato de votar. (grifo dos autores)
\end{abstract}

Em vez de a comunidade ficar apenas por esperar a crescente colaboração e das doações solidárias de outros atores sociais, principalmente do empresariado, esta mesma, por saber que "[...] vem ocorrendo uma mobilização cada vez maior do empresariado no tocante a ações de participação social para a solução de problemas que afetam os segmentos populacionais socialmente mais fragilizados no Brasil” (PINTO, 2003, p. 419), deve se movimentar para não ser encarada dentre as que dependem constantemente de ajuda de outrem, mas, entendida como dentre aquelas que necessitam de um apoio para desenvolverem seu potencial.

Neste sentido, é essencial que qualquer processo de construção da capacidade comunitária tenha como foco inicial os próprios moradores, pois comunidades fortes são o reflexo de pessoas e famílias saudáveis, que constroem ambientes mais harmoniosos, propiciando a formação de economias locais fortes e um desenvolvimento mais sustentável (NEUMANN; NEUMANN, 2004, p. 23).

Em outras palavras o capital social auxilia na construção dos relacionamentos existentes nas organizações sociais, não só quantitativamente quanto qualitativamente, com constante comunicação, troca de informações, comprometimento dos cidadãos e relacionamentos confiáveis e efetivos com empresas, o governo, o voluntariado e, "com o crescimento do turismo endógeno, essa relação venha se ampliando e permitindo a fruição de experiências mais autênticas e genuínas entre visitantes e população residente e autóctone" (BENI, 2006, p. 49). 


\section{4 ÁREA DE PROTEÇÃo AMBIENTAL DO MARACANÃ}

A Área de Proteção Ambiental (APA) do Maracanã foi criada através do Decreto Estadual 12.103 de Outubro de 1991, pelo Governo do Maranhão, devido à necessidade de proteger este local da constante ação degradante do homem para com o meio ambiente, na medida em que esta se situa próxima ao Distrito Industrial do Maranhão, da ALUMAR (Consórcio e Alumínio do Maranhão), e do Aterro Sanitário.

Na APA, fica localizado o bairro do Maracanã que está distante 25 quilômetros do centro de São Luís. A APA do Maracanã possui uma área de 1.831 hectares, abrangendo o bairro do Maracanã e áreas vizinhas. Ela está situada próxima ao mar e é cortada por dois rios: o rio Grande e o rio Maracanã.

Esta APA está inserida na região da Amazônia Legal, possuindo fauna e flora bem diversificadas. Sua fauna é composta por espécies de aves como juritis, rolinhas, pipiras azuis, e peixes acará, traíra e piaba. Inserida na zona de mata de galeria, a flora é composta de várias espécies de árvores frutíferas, leguminosas e gramíneas, além de vegetação de várzea, dando destaque ao buriti e à juçara.

A juçara possui importância para a comunidade do bairro, sendo que há mais de 35 anos, no mês de outubro acontece à tradicional Festa da Juçara no Parque da Juçara no Maracanã. Outra fonte de renda e grande atrativo são as trilhas ecológicas, onde são oferecidos passeios nos quais o visitante conhece a cultura e a história do Bairro do Maracanã, além de ter um contato direto com a natureza. Além destes, tem o tradicional bumba-meu-boi do Maracanã com seu barracão localizado na comunidade; a Festa dos Reisados que é uma homenagem ao Deus Menino no presépio, esta começa no dia 5 de janeiro, se estendendo até o dia 7 do mesmo mês; e a Festa do Divino.

A comunidade do bairro do Maracanã é de classe média baixa, no bairro é possível encontrar ruas sem estrutura básica como água encanada, esgoto e asfalto. Uma parte da sociedade trabalha no distrito industrial, por estar localizado próximo à localidade e outra parte, sobrevive da venda da juçara e do turismo. 


\section{METODOLOGIA}

Caracteriza-se como pesquisa empírica, com o contato direto com o ambiente em estudo (bairro), além de pesquisa bibliográfica e documental (livros, revistas, artigos, monografias, dentre outras fontes).

Quanto à abordagem é quantitativa e qualitativa com relação à análise dos dados. O universo da pesquisa foi o bairro do Maracanã, e a amostra foi de 50 pessoas da comunidade residente no bairro, mais precisamente no entorno do Parque da Juçara, por se tratar de um espaço turístico. A escolha dos entrevistados foi aleatória, com os moradores que por ali estavam ou passavam. A pesquisa foi realizada mediante aplicação de questionários com perguntas abertas e fechadas. Alguns entrevistados responderam todas as questões, outros em parte, por não terem total conhecimento do turismo no bairro. E alguns marcaram mais de uma opção nas respostas. A aplicação dos questionários foi realizada com a comunidade do bairro do Maracanã no mês de abril de 2007. O tratamento dos dados ocorreu em maio do mesmo ano, utilizando gráficos para ilustrar os mesmos. Posteriormente, o texto foi atualizado com novas fontes de pesquisa bibliográfica.

\subsection{ANÁLISE DOS DADOS}

No intuito de identificar os benefícios da atividade turística no bairro do Maracanã em prol do desenvolvimento local, tem-se no primeiro gráfico, uma evidência de como os cidadãos, se consideravam atuantes no desenvolvimento do turismo local. Questionados sobre seu papel com a atividade turística, 66\% afirmaram ter um papel ativo nesse processo, enquanto outros $34 \%$ revelaram não serem atuantes.

Um dos fatores para que a percentagem dos indivíduos atuantes no desenvolvimento do turismo no bairro não fosse maior, ocorreu devido estes ainda não compreenderem ou determinarem um objetivo comum para que se organizassem e o alcançassem de forma igualitária. Para que o processo de desenvolvimento turístico local fosse alcançado plenamente e de maneira duradoura seria necessário o engajamento de todos os atores (trade, sociedade, gestores políticos), principalmente a comunidade, de maneira tal, que esta se sentisse responsável pelo sucesso do processo. 
A comunidade participante na realização do turismo na localidade foi alvo de benefícios propiciados por esse engajamento comunitário, como a redução de custos, a multiplicação da valorização de suas características, melhorias na educação, construção de cidadãos saudáveis e capazes de enfrentarem as dificuldades do dia-a-dia, fazendo da comunidade um ambiente seguro e propício para a inter-relação consistente e verdadeira entre turistas e autóctones.

Diante dos benefícios advindos da participação comunitária, foi perguntado aos cidadãos se estes se sentiam favorecidos com a atividade turística desenvolvida no Maracanã, e, os dados coletados foram que, embora alguns ainda não fossem atuantes, $84 \%$ sentiam-se beneficiados e apenas $16 \%$ não possuíam benefícios do turismo. A abrangência dos ganhos em conseqüência do desenvolvimento da atividade tinha um alcance significativo, que embora os cidadãos que não atuavam, podiam percebê-los. Pois esta abrangência referia-se não só à economia, mas à educação, segurança, saúde, dentre outras vantagens, visando à melhoria na qualidade de vida.

Quando perguntados se o desenvolvimento turístico para a comunidade era positivo ou negativo, $90 \%$ informaram ser positivo, enquanto que $10 \%$ dos questionados negaram. Isto aconteceu pelo fato de que quando ocorre a participação efetiva da comunidade, desde o processo de tomada de decisões, há maior probabilidade de a população vislumbrar os impactos positivos do turismo.

De fato, viu-se que mesmo com o montante de $34 \%$ daqueles que não se consideravam atuantes no desenvolvimento do setor (primeira questão), no que tange aos benefícios e a visão positiva do turismo, foi visível uma tendência a aceitação deste, como fator de desenvolvimento local, por estimular constantemente o bem-estar social através da conciliação do crescimento econômico com o social, ambiental e cultural.

Dessa forma, sabendo que o desenvolvimento do turismo relaciona-se a fatores econômicos, participação de pessoas, dentre outros fatores, constatou-se que um total de $90 \%$ dos entrevistados acreditava no teor positivo do turismo. Então, perguntou-se sobre quais as mudanças positivas que aconteceram no bairro do Maracanã após o surgimento da atividade turística. As respostas indicaram que as melhorias relacionaram-se principalmente às questões econômica, social, ambiental e cultural, com respectivos 36 , 38,33 e 27 pontos percentuais (GRÁFICO 1). 


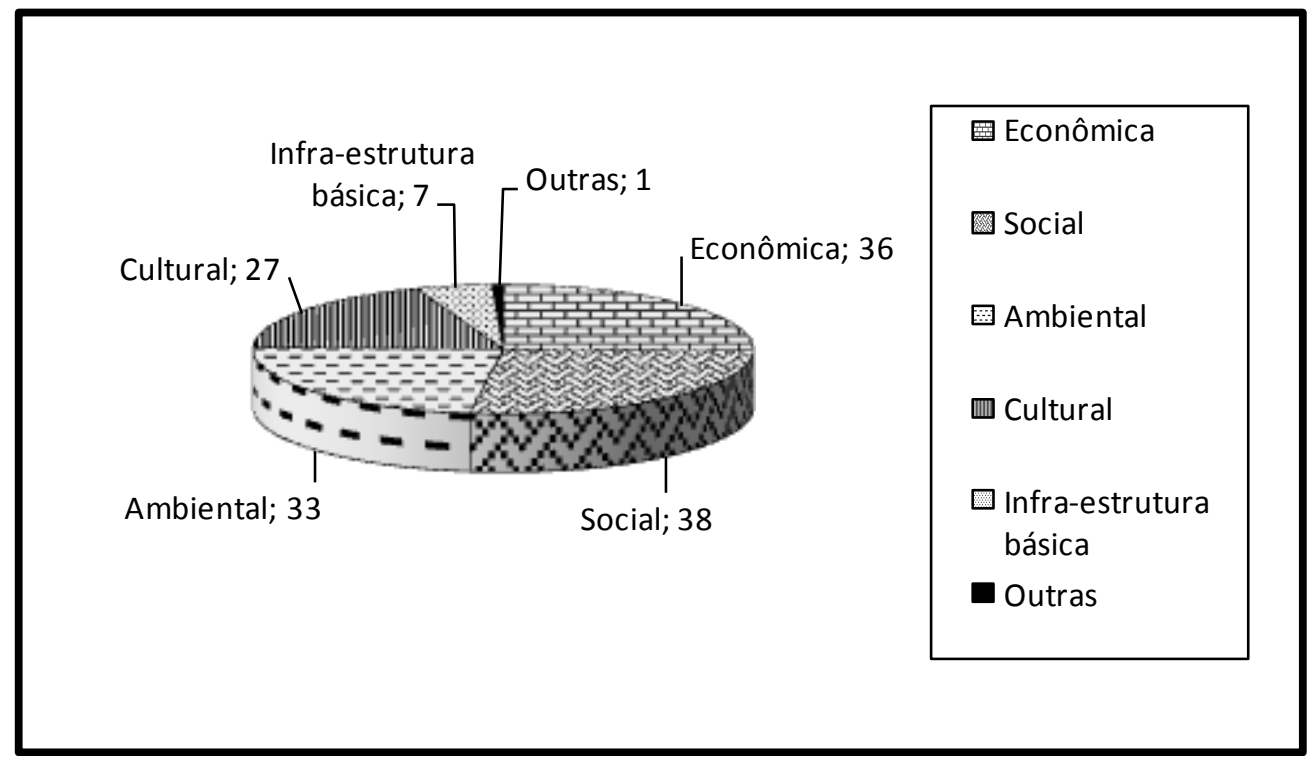

GRÁFICO 1 - MUDANÇAS POSITIVAS APÓS O SURGIMENTO DO TURISMO. FONTE: PESQUISA DE CAMPO, 2007.

$\mathrm{Na}$ economia, esses impactos podem ser evidenciados na ampliação e diversificação de postos de trabalho, e conseqüentemente no aumento da distribuição de renda, e em investimentos locais. No âmbito sociocultural, viu-se um maior apoio em relação à cultura, suas festas e à identidade local, bem como melhorias nas instalações médicas, educacionais e outras que aprimoram a qualidade de vida da população. Já no ambiental, gera uma maior conscientização e sensibilização da comunidade e dos visitantes para com a proteção da natureza e de seus espaços físicos.

Por outro lado, a atividade turística também pode acarretar impactos negativos à comunidade como degradação cultural e ambiental, caso esta não proporcione real importância ao desenvolvimento do turismo no ambiente em que vivem. Assim, quanto às mudanças negativas que aconteceram no bairro do Maracanã, após o surgimento do turismo, a grande maioria queixou-se da infra-estrutura básica com $34 \%$, ou seja, as melhorias pretendidas não apareceram, e com relação à cultura, o resultado demonstrou que se obtiveram ganhos, mas que seria necessária uma maior atenção a este dado, pois apareceu com $15 \%$, ou seja, melhorou, mas a cultura, ainda precisava ser trabalhada e incentivada no bairro (GRÁFICO 2). 


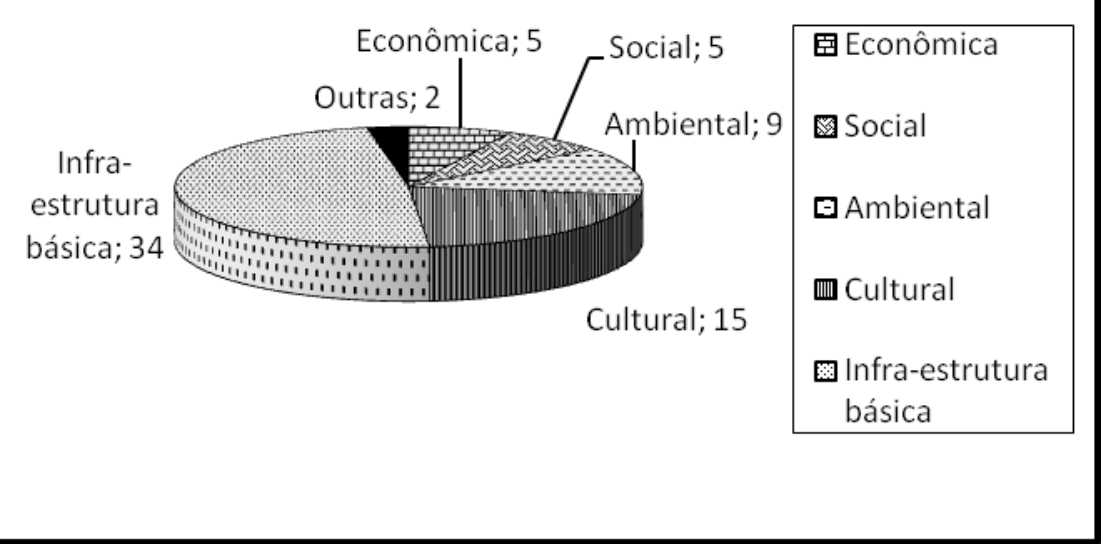

GRÁFICO 2 - MUDANÇAS NEGATIVAS APÓS O SURGIMENTO DO TURISMO. FONTE: PESQUISA DE CAMPO, 2007.

Durante a aplicação dos questionários, identificou-se que as pessoas viam o turismo como um fenômeno que promoveria mudanças qualitativas para o bairro, principalmente com relação à qualidade de vida e o bem-estar dos mesmos, claramente ligadas a questões socioeconômicas, culturais e ambientais.

Desta feita, buscou-se saber como a atividade turística tinha impulsionado melhorias sociais para a comunidade do Maracanã, chegando-se a respostas como (ordem decrescente de pontuação), conforme demonstrado no gráfico 3 a seguir.

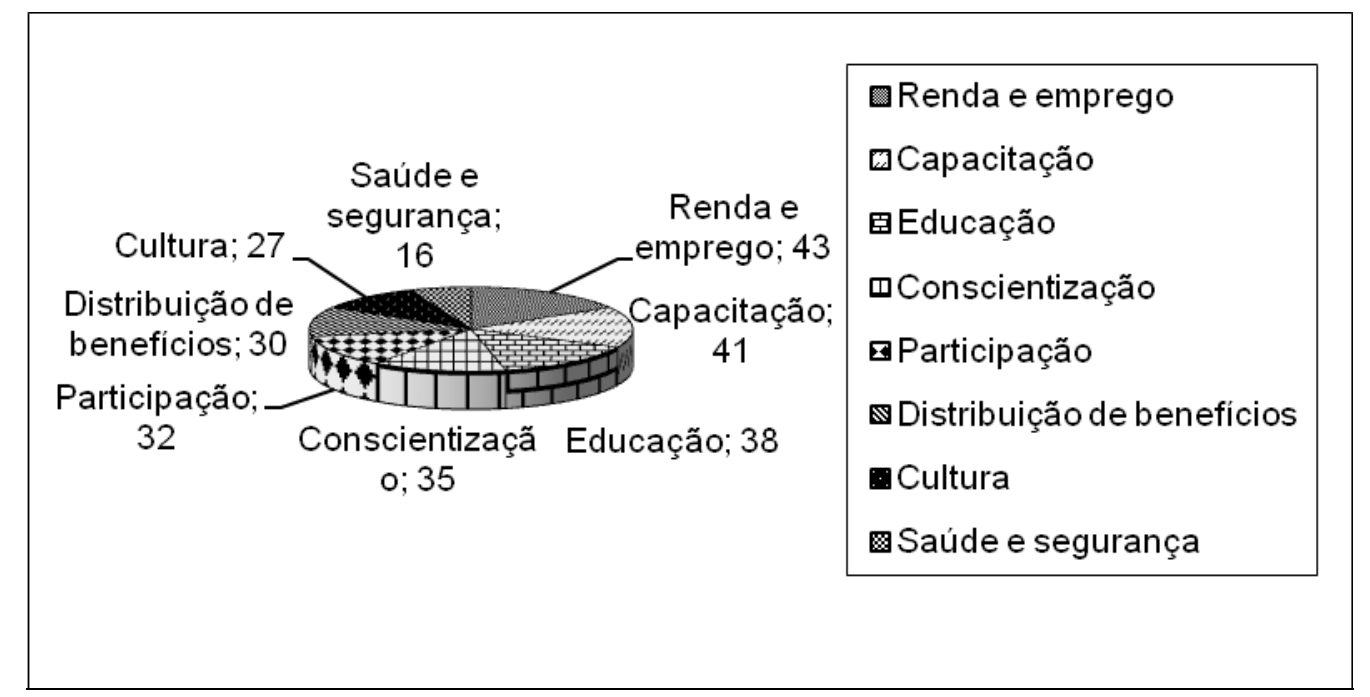

GRÁFICO 3 - MELHORIAS SOCIAIS ADVINDAS DA ATIVIDADE TURÍSTICA. FONTE: PESQUISA DE CAMPO, 2007.

Através das respostas obtidas, percebeu-se o potencial que o bairro possuía para o desenvolvimento da atividade turística, pois como foi identificado houve o surgimento 
dos impactos positivos como emprego e renda (43\%) e a melhoria de serviços básicos como a educação (38\%), somados a percepção destas modificações pelos autóctones, condições essas essenciais para o desenvolvimento local.

Todavia, não se poderia deixar de abordar sobre de que maneira foi desenvolvida a atividade turística no bairro do Maracanã, para relatar através de quais ações ou eventos, a comunidade adquiriu conhecimento do verdadeiro envolvimento do setor com o aproveitamento das peculiaridades da localidade e participação do autóctone. Para tal questionamento identificaram-se diversas iniciativas, tais como a Festa da Juçara (50\%), a própria juçara e seus atrativos (50\%), as trilhas ecológicas (48\%), o Projeto Maracanã (45\%), o bumba-meu-boi de Maracanã (32\%), a Festa do Divino (26\%) e os Reisados (20\%), como as principais ações pelas quais ocorre o desenvolvimento turístico e local, evidenciados a partir do exposto no gráfico 4.

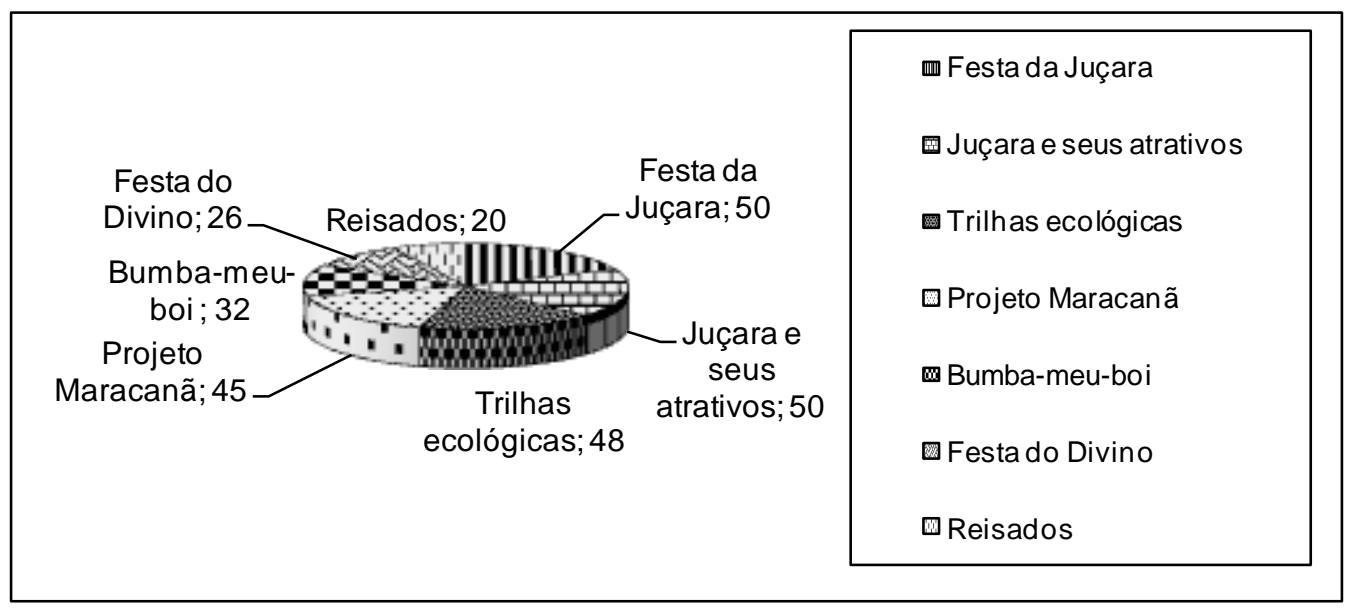

GRÁFICO 4 - MANEIRAS PELAS QUAIS É DESENVOLVIDO O TURISMO NO MARACANÃ. FONTE: PESQUISA DE CAMPO, 2007.

Estas atividades desenvolvidas no Maracanã promovem uma eqüidade no desenvolvimento local na medida em que envolvem a comunidade nas atividades turísticas, desde o processo de planejamento até a execução, contando com o apoio do poder estatal. A RS voltada para o protagonismo comunitário aparece então, no instante em que os poderes público e privado apóiam eventos e iniciativas como os identificados no bairro, além de proporcionar atividades constantes de sensibilização, treinamentos, entre outras que acrescentam conhecimento a estes cidadãos. Os acontecimentos que foram identificados no Maracanã são na sua maioria organizados, promovidos e executados por indivíduos da própria comunidade. 
$\mathrm{E}$, ao se pensar na valorização da atividade turística aliada a responsabilidade social, se faz necessário o desenvolvimento desta vertente visando o contínuo e adequado andamento das ações para o bem-estar social. Assim, indagou-se a comunidade se acreditavam que a prática do turismo viria a contribuir com o desenvolvimento sustentável e local, onde uma minoria de $12 \%$ respondeu que não e inversamente a isto, os outros $88 \%$ mencionaram acreditar sim nesta prática.

O motivo pelo qual levou a maioria destas pessoas a acreditarem no desenvolvimento sustentável do turismo na localidade foi o desenvolvimento de trabalhos como o Projeto Maracanã ${ }^{9}$, com suas trilhas e ações de sensibilização dos visitantes e dos autóctones a respeito do turismo. Mencionaram acreditar também nesse teor sustentável pelo fato do turismo valorizar sua cultura, meio ambiente, estilo de vida e a própria população.

Devido aos cidadãos acreditarem no desenvolvimento sustentável e responsável do turismo, enfatizando-os como atores principais da cadeia do turismo, para tal acontecimento, é que se dá a devida importância da participação da comunidade no processo de planejamento das ações a serem realizadas na sua localidade, pois estes são responsáveis por desenvolverem objetivos que beneficiem a todos os moradores locais e se tornarem mais independentes não permitindo que a tomada de decisões fique apenas sob encargo dos gestores, mas sim, juntos conquistarem o desenvolvimento sustentável e local, com base na responsabilidade social.

\section{CONCLUSÃO}

A relação do turismo com a questão social é de importância crucial para o equilíbrio do melhor desempenho da atividade, pois trazer a sociedade para o sistema turístico facilita a maximização dos efeitos positivos. Assim, a valorização da atividade turística aliada à responsabilidade social é um dos passos para a promoção do desenvolvimento local eqüitativo, através do comportamento socialmente responsável do turismo. Neste sentido, o compromisso do turismo com o desenvolvimento local,

\footnotetext{
${ }^{9}$ Projeto Maracanã - ações da Secretaria Municipal de Turismo no bairro do Maracanã, como a criação das trilhas ecológicas, o incentivo a Festa da Juçara e da manifestação do bumba-meu-boi. Apoio a atividades de educação ambiental em escolas do bairro.
} 
extrapola as barreiras da relação visitante e visitado, já que a demanda dos turistas ocorre mediante a percepção da imagem de cada lugar no momento de sua escolha.

Vê-se que uma maioria se considerou atuante no processo de desenvolvimento do turismo local e que percebiam os efeitos positivos e a abrangência dos benefícios proporcionados pela atividade, sem contar nas mudanças ocorridas no Maracanã após o surgimento desta, principalmente no que tange as questões sócio-econômicas, culturais e ambientais.

Identificou-se também, as formas pelas quais estava sendo desenvolvido o turismo na localidade, privilegiando as potencialidades locais e a participação comunitária, bem como foi de suma importância se registrar a atividade turística como "mola propulsora" de melhorias sociais, indo da geração de emprego e renda, passando por ações que envolviam a comunidade (capacitação, conscientização e participação), chegando-se as melhorias na educação, saúde e segurança, mais a distribuição dos benefícios.

Portanto, conclui-se que, a atividade turística valendo-se do seu poder persuasivo e embasada em ações socialmente responsáveis, fazendo dos indivíduos de cada localidade cidadãos ativos e conscientes do seu papel e tendo como base a realidade do turismo na comunidade do Maracanã, teve-se a proposta da atual pesquisa confirmada, propondo-se a valorização da atividade turística aliada à responsabilidade social como ferramenta para o desenvolvimento local, responsável e sustentável.

\section{REFERÊNCIAS}

ABREU, C. B. Reflexões e propostas para um planejamento turístico com competência profissional e responsabilidade social. In: AGUIAR, M. de F.; BAHL, M. (Orgs.). Competência profissional no turismo e compromisso social: coletânea do XXVI CBTUR - Congresso Brasileiro de Turismo 2006. São Paulo: Roca, 2006. p. 351-358.

ARANHA, M. L. de A.; MARTINS, M. H. P. Temas de filosofia. 3. ed. São Paulo: Moderna, 2005.

BARBOSA, F. F. O turismo como um fator de desenvolvimento local e/ou regional. In: Caminhos de Geografia - revista on-line, fev. 2005. Disponível em: <http://www.ig.ufu.br/caminhos_de_geografia.html>. Acesso em: 21/03/2007.

BENI, M. C. Políticas e planejamento de turismo no Brasil. São Paulo: Aleph, 2006. 
CAMPOS, M. M. da C. e. Processo de desenvolvimento local: uma análise da implementação do projeto aliança com o adolescente. 2003. Disponível em: <http://www.adm.ufba.br/marcia_maria2.pdf>. Acesso em: 20/03/2007.

FISCHER, R. M. Novas dimensões da responsabilidade social: a responsabilidade pelo desenvolvimento. In: MACHADO FILHO, C. P. Responsabilidade social e governança: o debate e as implicações. São Paulo: Pioneira Thomson Learning, 2006. p. 151-166.

LAGE, B. H. G.; MILONE, P. C. Economia do turismo. 7. ed. São Paulo: Atlas, 2001.

MACHADO FILHO, C. P. Responsabilidade social e governança: o debate e as implicações. São Paulo: Pioneira Thomson Learning, 2006.

NEUMANN, L. T. V.; NEUMANN, R. A. Repensando o investimento social: a importância do protagonismo comunitário. São Paulo: Global; IDIS - Instituto para o Desenvolvimento Social, 2004.

OMT. Turismo internacional: uma perspectiva global. 2. ed. Porto Alegre: Bookmann, 2003.

PENA JÚNIOR, M. A. G.; VÁLERY, D. F. Responsabilidade social e desenvolvimento local: a necessidade de uma pró-atividade empresarial. Revista Virtual de Gestão de Iniciativas Sociais. 3. ed. jun. 2005. Disponível em: <http://www.ltds.ufrj.br/gis/anteriores/rvgis3.pdf>. Acesso em: 25/03/2007.

PINTO, L. F. da S. Gestão cidadã: ações estratégicas para a participação social no Brasil. 2. ed. Rio de Janeiro: FGV, 2003.

RUSCHMANN, D. V. de M. Planejamento e turismo sustentável: a proteção do meio ambiente. 11. ed. Campinas, SP: Papirus, 1997.

RUSCHMANN, D. V. de M.; PHILLIPI JR., A. Gestão ambiental e sustentabilidade no turismo. São Paulo: Manole, 2009.

SILVA, Y. F. e; BOIA, Y. I. K. Turismo e responsabilidade social: uma reflexão sobre os direitos das pessoas com necessidades especiais. In: RUSCHMANN, D. V. de M.; SOLHA, K. T. (Orgs.). Planejamento turístico. Barueri, SP: Manole, 2006.

SILVEIRA, M. A. T. da. Planejamento territorial e dinâmica local: bases para o turismo sustentável. In: RODRIGUES, A. B. (Org.). Turismo e desenvolvimento local. 3. ed. São Paulo: Hucitec, 2002.

SOLHA, K. T. Política de turismo: desenvolvimento e implementação. In: RUSCHMANN, D. V. de M.; SOLHA, K. T. (Orgs.). Planejamento turístico. Barueri, SP: Manole, 2006. p. 89-100. 
SOUSA, L. da S. Turismo e desenvolvimento local sustentável na Paraíba. Edição eletrônica, 2006. Disponível em: <http://www.eumed.net/libros/2006/iss/1c.htm>. Acesso em: 19/03/2007.

VERGARA, S. C. Projetos e relatórios de pesquisa em administração. 7. ed. São Paulo: Atlas, 2006.

ZAPATA, T. 2004. Estratégias de desenvolvimento local. Disponível em: $<$ http://www.cati.sp.gov.br/novacati/pemh/doc_pub/Estrategias\%20de\%20Desenvolvimento \%20Local.pdf>. Acesso em: 20/03/2007.

Recebido em: 01-10-2010.

Aprovado em: 01-11-2010. 